\title{
ELECTROCARDIOGRAMS OF HEALTHY MEN AFTER STRENUOUS EXERCISE
}

\author{
BY \\ C. A. RUMBALl AND E. D. ACHESON \\ From the Central Medical Establishment, Royal Air Force \\ Received August 7, 1959
}

Between August 1954 and May 1957, 682 R.A.F. officers and men volunteered for a study of the electrocardiogram after exercise. Of these, 660 were selected because they had no symptoms, no clinical or radiological evidence of heart disease, a diastolic blood pressure of below $100 \mathrm{~mm}$. $\mathrm{Hg}$, and a normal 12-lead electrocardiogram taken at rest. Certain minor electrocardiographic changes that are believed to have a good prognosis when unaccompanied by other evidence of heart disease (Packard et al., 1954; Manning, 1954) did not disqualify. The frequency of these changes was as follows:-Wolff-Parkinson-White syndrome (1), complete right bundle-branch block (2), incomplete right bundle-branch block (33), P-R of 0.2 to $0.23 \mathrm{sec},(11)$, and left axis deviation (10). In addition, slurring of $R$ in lead $I$ was present in 5 and minor anomalies of the $T$ wave in 25 .

Four hundred and fifteen of the men were officers and 245 airmen. Their ages ranged from 19 to 54 years (mean $37 \cdot 2 \pm 5.6$ years). A preliminary account of the first 540 cases has been published (Acheson, 1957) and a follow-up study is in progress.

\section{EleCtrocardiographic TeChNIQUe aNd CRITERIA}

After a standard 12-lead cardiogram had been recorded on a direct-writing instrument, the men ran down and up a staircase of 66 steps, each 10 inches high, under medical supervision. They were permitted to choose their own pace, but were instructed to complete the course as fast as possible without having to take a rest en route. The first 57 men in the $40-49$ age group and all those 50 years old or more performed a single trip; the remainder completed the trip twice. The time taken to cover the distance was recorded by stop watch. The 531 men who performed the double test took an average of $85.3 \pm 15.4$ seconds. The 109 men who did the single test took an average of $48 \cdot 6 \pm 14 \cdot 4$ seconds. There were no accidents.

The tracings after exercise were repeatedly recorded in series (I, II, III, V4, V5, V6) commencing 1 minute, 3 minutes, and 6 minutes after completion of the exercise. Deviations of the RS-T segment were measured using the junction of the P-R segment with the QRS complex as the point of reference, thus avoiding errors due to a negative auricular T wave (Scherf and Schaffer, 1952). Measurements were taken from three successive complexes where the baseline was steady, the mean was calculated and recorded to the nearest half millimeter.

RS--T junction ("J") depression was defined as depression of the junction between RS and T when the remainder of the RS-T segment sloped upwards to the peak of the T wave (Fig. 1A). RS-T segment depression was defined as flat or sagging depression of the whole RS-T segment (Fig. 1C). In 5 tracings it was impossible to make the distinction between " $J$ " depression and depression of the. RS-T segment as defined (Fig. 1B). These cases were, therefore, relegated to the unclassifiable group (Group D). T waves were classified as upright, iso-electric, or negative. When T-wave anomalies occurred after exercise without RS-T segment depression they were termed "isolated T-wave changes" (Fig. 1D). 
As a result of an analysis of the electrocardiogram after exercise 90 cases (13.6 per cent) were set aside for further study. Of these, 78 showed at some point at least one of the following changes in one or more leads other than lead III : (1) $0.5 \mathrm{~mm}$. RS-T segment depression; or (2) iso-electric or negative $T$ waves. In 12 cases the tracings were unsatisfactory owing to variation in the baseline. To determine the reproducibility of the changes, all 90 men were invited to attend again. Sixtythree accepted and a second tracing after exercise was obtained. It was found that men whose tracings had shown RS-T segment depression of at least $1 \mathrm{~mm}$. or iso-electric or negative $\mathrm{T}$ waves on the first occasion were likely to show comparable anomalies on a second occasion (Fig. 2), but that eight of those who had shown RS-T segment depression of only $0.5 \mathrm{~mm}$. initially had no RS-T depression after the second exercise test. It was therefore possible to distinguish between a consistently anomalous group (Group B) and a borderline group (Group C). The criteria for inclusion in Group B are similar to those adopted by Wood et al. (1950) for the diagnosis of myocardial ischæmia from the post-exercise electrocardiogram of patients with chest pain. There remained 20 tracings that were unclassifiable (Group D). The vast majority of the tracings (which showed neither depression of the whole RS-T segment nor T wave changes) were classified in Group A (Table I). 


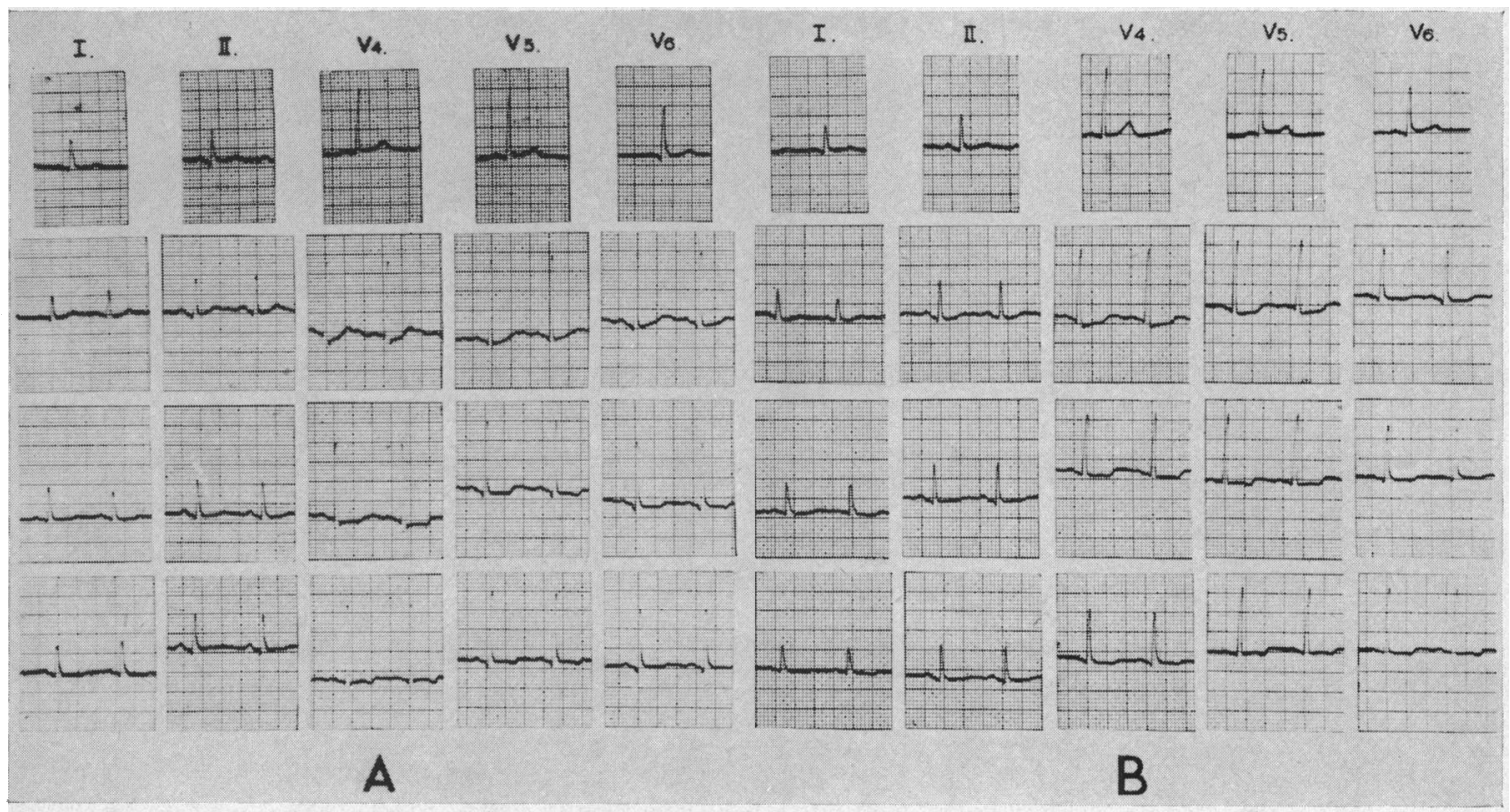

FIG. 2.-Case 895 (Group B-2). (A.) 8.4.57. (B.) 15.4.57. These tracings illustrate the reproducibility of the anomalies after an interval. Note the similarity of the changes to those in Fig. 6.

In view of the finding of Robb and his colleagues (1956) that patients with isolated $\mathrm{T}$ wave changes after exercise have as good a prognosis as those with normal tracings, it was decided to separate these from the remainder of Group B. The final classification adopted is shown in Table I.

TABLE I

Classification of the Electrocardiograms after Exercise in 660 Apparently Healthy Men

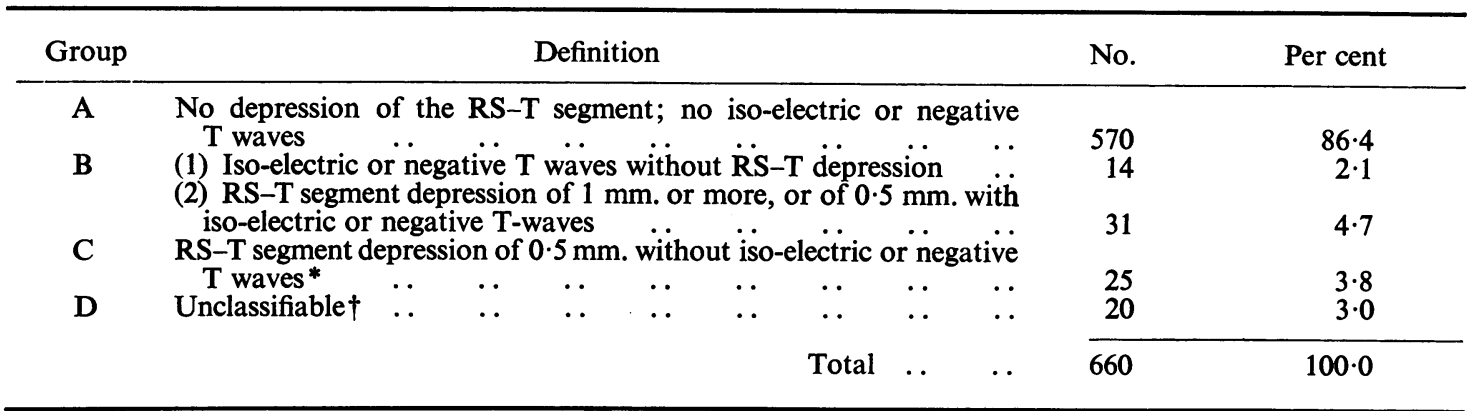

* Included 7 subjects with RS-T depression limited to leads II and III.

$\dagger$ Eight cases with $0.5 \mathrm{~mm}$. depression on first occasion and normal tracings on second; 5 cases with unclassifiable RS-T depression (Fig. 1B); 7 cases with marked baseline variation, and a suspicion of RS-T depression.

Age. The age distribution of the men with anomalous tracings after exercise is given in Table II. RS-T segment depressions are commoner in the older age groups; isolated $\mathrm{T}$ wave anomalies are not.

In interpreting the apparent increase in frequency of RS-T segment depression with age, the complication arises that the subjects of the survey were not all obtained by exactly the same method. The first 300 men (aged 19-39) were successful applicants for extension of service and had just 
passed a medical board. The next 240 volunteers (aged 40-54) were obtained by station medical officers and this sample contained more airmen and fewer officers. To test whether the higher frequency in the older men was due to differences other than age, a third sample of 120 men from 30 to 54 years of age was obtained from the station medical officers. When the two samples from

TABLE II

- The Relationship of the Types of Anomaly to Age

\begin{tabular}{c|c|c|c|c|c|c|c}
\hline $\begin{array}{c}\text { Age } \\
\text { group }\end{array}$ & $\begin{array}{c}\text { Total No. } \\
\text { of cases }\end{array}$ & $\begin{array}{c}\text { Total No. } \\
\text { cases RS-T } \\
\text { depression }\end{array}$ & $\begin{array}{c}\text { Per } \\
\text { cent }\end{array}$ & $\begin{array}{c}\text { RS-T } \\
\text { depression } \\
1 \text { mm. or } \\
\text { more }\end{array}$ & $\begin{array}{c}\text { Per } \\
\text { cent }\end{array}$ & $\begin{array}{c}\text { Isolated } \\
\text { T-wave } \\
\text { changes }\end{array}$ & $\begin{array}{c}\text { Per } \\
\text { cent }\end{array}$ \\
\hline $19-24$ & 83 & 3 & $(8 \cdot 6)$ & 1 & $(1 \cdot 2)$ & 1 & $(1 \cdot 2)$ \\
$25-29$ & 64 & 2 & $(3 \cdot 2)$ & 1 & $(1 \cdot 6)$ & 3 & $(4 \cdot 7)$ \\
$30-34$ & 151 & 3 & $(2 \cdot 0)$ & 3 & $(2 \cdot 0)$ & 4 & $(2 \cdot 6)$ \\
$35-39$ & 78 & 6 & $(7 \cdot 7)$ & 1 & $(1 \cdot 3)$ & 2 & $(2 \cdot 6)$ \\
$40-44$ & 126 & 17 & $(13 \cdot 6)$ & 7 & $(5 \cdot 6)$ & 1 & $(0.8)$ \\
$45-49$ & 99 & 14 & $(14 \cdot 0)$ & 8 & $(8 \cdot 0)$ & 3 & $(3 \cdot 0)$ \\
$50-54$ & 59 & 11 & $(18 \cdot 6)$ & 4 & $(6 \cdot 8)$ & 0 & $(0 \cdot 0)$ \\
\hline
\end{tabular}

the stations were combined (360 men aged 30-54) an increase in RS-T segment depression with age was again demonstrated. The overall frequency in the age group 30-39 was 7 per cent (5 cases in 76); for the $40-54$ age group it was 15 per cent (42 cases in 284). For RS-T depression of $1 \mathrm{~mm}$. or more the proportions were 1.3 per cent and 6.7 per cent respectively. In both cases, the difference between the percentages is significant $(P<0.05>0.01)$. It has been concluded that age is probably one factor in the higher frequency of RS-T segment depression in older men.

\section{PATterns of ReSPONSE of EleCtrocardiogram AFTER EXERCISE}

(a) Isolated $T$ wave Changes. Iso-electric or negative $\mathrm{T}$ waves without RS-T depression occurred in 14 cases (Group B-1). These changes were seen most commonly in lead V6, less commonly in V5 and II, and rarely in leads I and V4. Inversion was always shallow and never exceeded $1.5 \mathrm{~mm}$. True inversion was never seen in lead I.

(b) $R S-T$ Segment Depression. Fifty-six men showed RS-T segment depression of $0.5 \mathrm{~mm}$. or more (Groups B-2 and C). In every instance this was accompanied or followed by a demonstrable change in the shape of the $\mathrm{T}$ wave. The depression was most commonly seen in V6 and became progressively less frequent across the chest from left to right. It was common in lead II, but rare in lead I, and when present was less than $1 \mathrm{~mm}$. (Fig. 3).

In seven cases depression was limited to lead II. These were the only cases in which there was an obvious relationship between the type of post-exercise response, and the electrical position of the heart. All seven had vertical heart patterns in the unipolar leads with an S wave in lead I and a tall $R$ wave in leads II and III.

The most common type of T-wave anomaly encountered in association with RS-T segment depression was a deformity of the ascending limb of the $\mathrm{T}$ wave, but a definite negativity was seen on 35 occasions. An iso-electric T occasionally accompanied RS-T segment depression in other leads. The maximum change in T usually occurred later than the maximum degree of RS-T depression and some deformity was often still apparent when RS-T depression had disappeared.

(c) Depression of " $J$ ". Transitory depression of " $J$ " after exercise was extremely common (Fig. 4). A special study of it was made in the last 120 consecutive cases. Owing to the obtuse angle between the upstroke of $S$ and the ascending limb of $T$ in these cases it was impossible to measure accurately degrees of depression of " $J$ " less than $1 \mathrm{~mm}$. Fifty per cent of the 120 tracings 


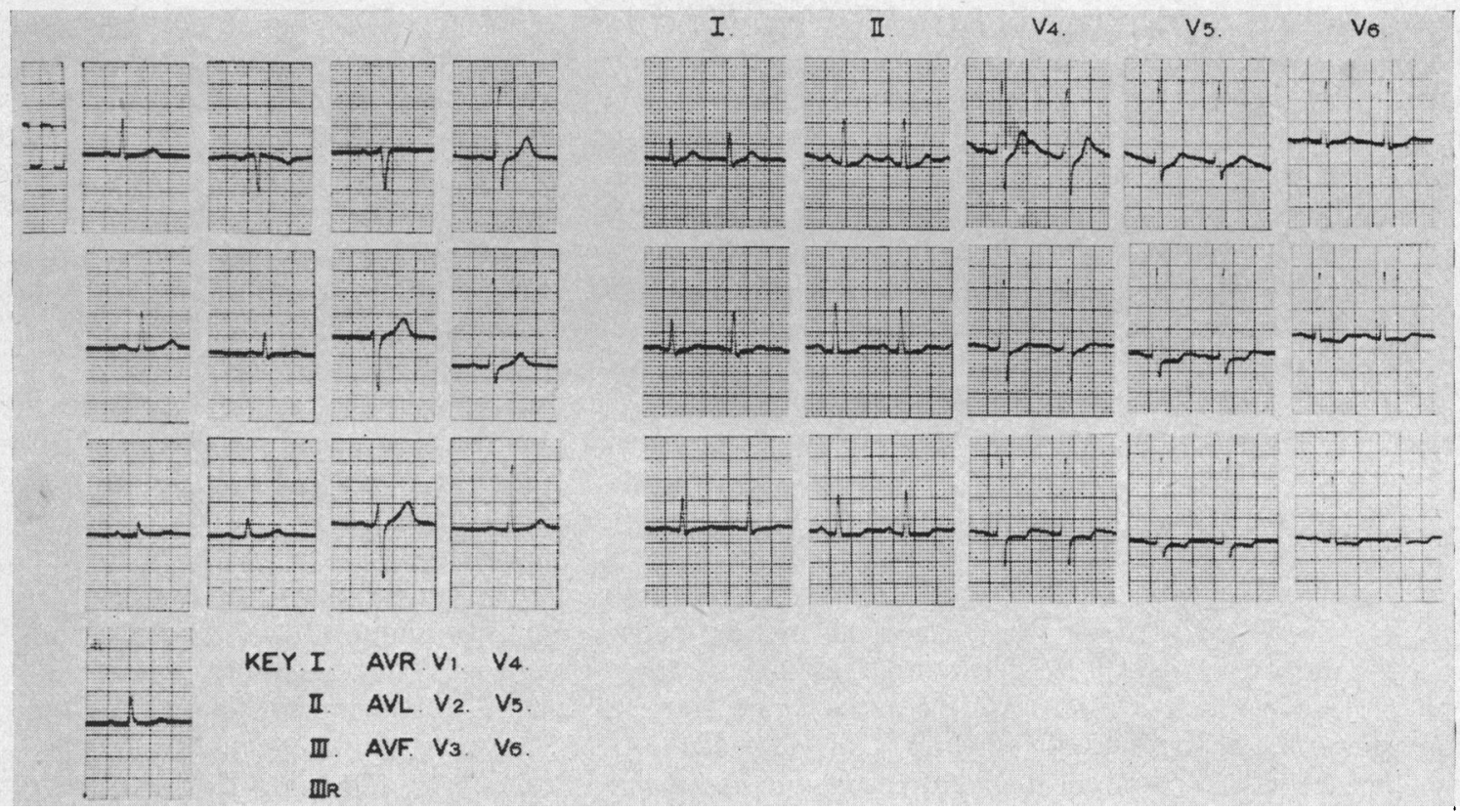

Fig. 3.-Case 605.1 (Group B-2). Left-13-lead cardiogram at rest. Right-5-leads from above downwards 1 min., $3 \mathrm{~min}$., and $5 \mathrm{~min}$., after exercise. RS-T segment depression of $1 \mathrm{~mm}$. after exercise with $0.5 \mathrm{~mm}$. depression in II and V4.

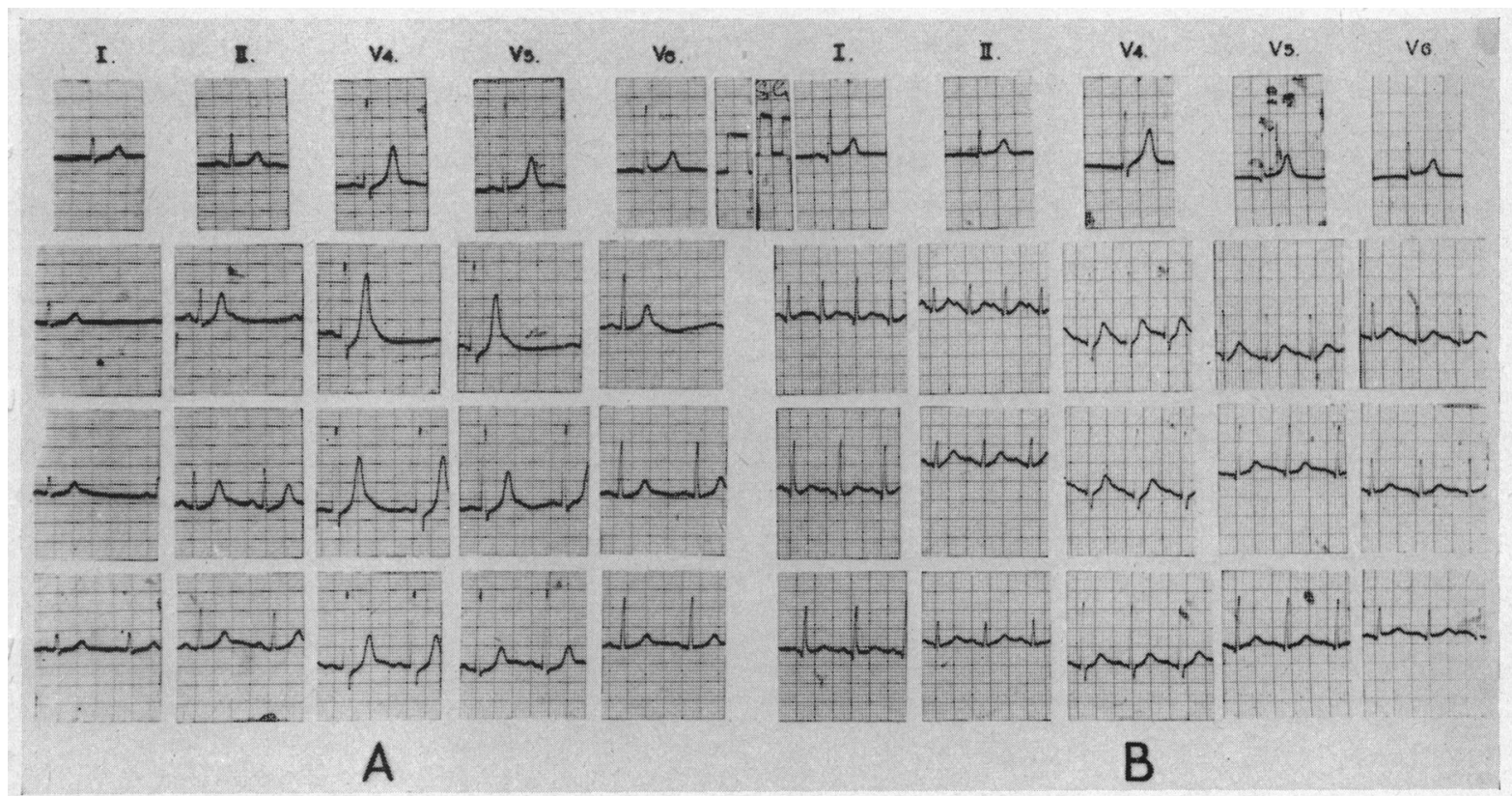

FIG. 4.- These two tracings illustrate the normal response of the electrocardiogram to exercise. (A.) Case 808, marked " $\mathrm{J}$ " depression 1 minute after exercise which quickly diminishes: heart rate one minute after exercise 55 . (B.) "J" depression absent; heart rate one minute after exercise 150. 
analysed had " $\mathrm{J}$ " depression of $1 \mathrm{~mm}$. or more in at least one lead. It is commonest where a large S wave is usually found, occurring not at all in lead I; in 18 per cent in lead II; 39 per cent in V4; 33 per cent in V5; and 10.5 per cent in V6.

The contrast between the pattern of distribution of "J" depression and RS-T segment depression was striking. While RS-T segment depression became progressively more common from lead V4 to V6, the reverse was true of " $\mathrm{J}$ " depression. There was also a marked contrast in the temporal evolution of the two types of depression. " $\mathrm{J}$ " depression was invariably maximal in the initial post-exercise tracing and almost always declined rapidly. On the other hand, RS-T segment depression was seen in only two cases in the initial recording. In the remainder it did not appear until at least 3 minutes after exercise and in 40 cases it was still present after 6 to $7 \frac{1}{2}$ minutes.

It has been said that " $\mathrm{J}$ " depression is related to the tachycardia that commonly follows exertion (Scherf and Schaffer 1952). Fig. 4B illustrates that other factors are also involved.

(d) Arrhythmias after Exercise. A frank arrhythmia after exercise was noted in four instances ( 0.6 per cent). One man showed the typical pattern of accelerated atrio-ventricular conduction at rest (Wolff-Parkinson-White syndrome). After exercise, accelerated and normal conduction was seen in alternate beats. There were also short runs of ventricular tachycardia. Another subject developed a paroxysm of atrial fibrillation which ceased five minutes later. A third man showed long periods of alternating nodal and sinu-atrial beats; and a fourth exhibited short runs of ventricular tachycardia. The last two subjects mentioned also developed isolated T-wave changes in their post-exercise tracings.

One or more ectopic beats were recorded at rest or after exercise in 109 cases (16.5 per cent). In 13 ( 2 per cent) they were observed on the resting tracing and were abolished by exercise; in 18 cases ( 3 per cent) they were present both at rest and after exercise. In 78 cases (12 per cent) they were absent at rest but present after exercise, when they were usually seen in the early part of the tracing when the tachycardia was greatest.

\section{Plasma Cholesterol}

After the electrocardiographic study had been completed, plasma cholesterol was determined in 32 men in Group B and in 98 members of Group A. The remaining 13 men in B had either been posted to remote stations or abroad, or refused the blood examination. The sample from Group A was derived by selecting a batch of men to match the age of each man in Group B. Figures for $12 \mathrm{men}$ in Group C $(257.2 \pm 45.2 \mathrm{mg}$. per $100 \mathrm{ml}$.) have been excluded because, owing to an oversight, 6 of the 25 men in this Group were not given an opportunity to attend for this examination.

Eighteen millilitres of venous blood were taken in a dry syringe at least two hours after the last meal and placed in a container with $3 \mathrm{ml}$. of acid citrate dextrose buffer. The cholesterol was extracted by Bloor's method (1916) and estimated by the Lieberman-Burchard (1885) colorimetric method. The biochemist was given no information about the origin of the specimens until the analyses were complete.

The number of specimens, the mean plasma cholesterol together with the standard deviation,

TABLE III

The Plasma Cholesterol in Various Electrocardiographic Groups

\begin{tabular}{c|c|c|c|c}
\hline Group & $\begin{array}{c}\text { Number of } \\
\text { cases }\end{array}$ & $\begin{array}{c}\text { Mean cholesterol mg. } \\
\text { per cent }\end{array}$ & $\begin{array}{c}\text { S. D. mg. } \\
\text { per cent }\end{array}$ & Mean age \\
\hline A & 98 & $254 \cdot 9$ & $\pm 40 \cdot 3$ & $40 \cdot 6$ \\
B & 32 & $267 \cdot 6$ & $\pm 4 \cdot 1$ & $41 \cdot 3$ \\
B-1 & 6 & $230 \cdot 7$ & $\pm 21 \cdot 4$ \\
\hline Total & 26 & $276 \cdot 2$ & $\pm 42 \cdot 0$ & $43 \cdot 9$ \\
\hline
\end{tabular}


and the mean age in each group are shown in Table III. The mean for the series was $258 \pm 42 \mathrm{mg}$. per $100 \mathrm{ml}$. which is substantially higher than that found by Oliver and Boyd (1953) in apparently healthy British men and by Keys et al. (1950) in symptomless American men of comparable age, but lower than that found in a survey of American Army officers (Jencks et al. 1956).

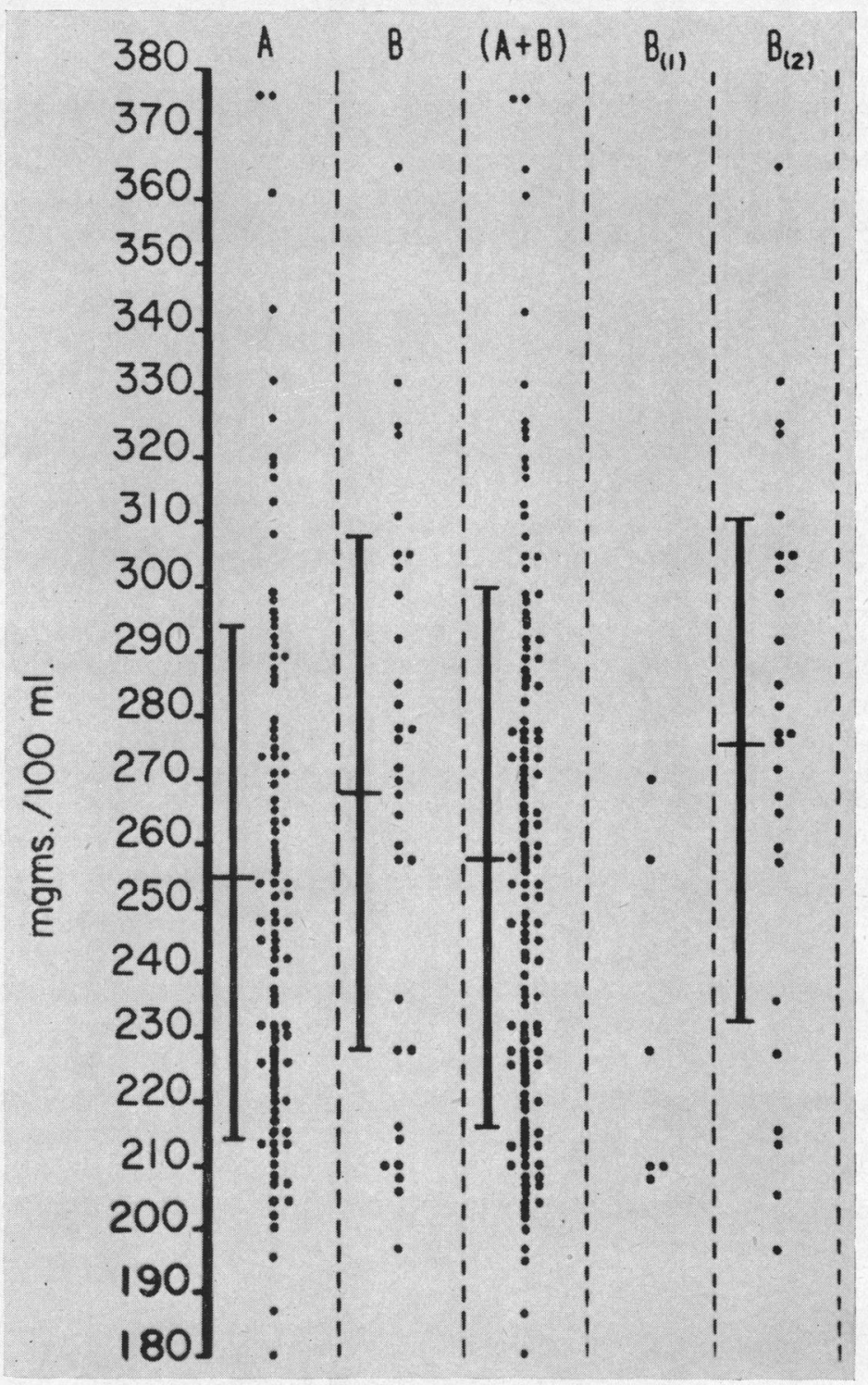

Fig. 5.-The range of plasma cholesterol in 130 men from Groups A and B. The means and standard deviations are indicated.

In view of the evidence (Keys et al., 1950; Lawry et al., 1957) that in men cholesterol increases from youth to middle age, the relationship of cholesterol to age was examined in our material. Although a slight trend in favour of an increase with age was noted, it was not significant in this small series.

From Table III it can be seen that the mean plasma cholesterol is higher in Group B than in 
Group A. This difference is not significant $(P>0.05)$. It is interesting, however, that when Group B is subdivided, the difference between the means of Group B-2 and Group A is significant $(P<0.05>0.01)$. In case the slightly higher mean age in Group B-2 contributed to this difference, each man in Group B-2 was matched against the mean cholesterol of all the men of similar age in Group A. A difference of the same statistical order was again demonstrated. Scatter diagrams of plasma cholesterol in the various electrocardiographic groups are shown in Fig. 5.

\section{Negative Evidence Bearing on the Significance of the Changes in Groups B and C}

The fact that 57 men aged 40-49 years mounted the staircase once and 168 men of comparable age performed the double exercise test gave an opportunity to study the effect of the amount of exercise on the frequency of anomalous post-exercise tracings. The yield of anomalies was similar after the single and double tests.

The time taken by each man to complete the exercise was also studied. No significant difference in rate of exertion between Group A and Groups B and C was found in any age group. The groups were also compared with negative results in respect of rank, height, weight, and the amount of physical exercise taken in the previous three months.

A comparison of the prevalence of coronary artery disease in the families of the various groups in the first 540 cases revealed a materially higher prevalence in the relatives of men in Groups B and $C$ (Acheson, 1957). Although a trend is still present for the completed series, the difference in familial prevalence of coronary artery disease between Group A and Groups B and C in the completed series is not statistically significant.

Following the results of Wasserburger and Lorenz (1956), an attempt was made to reproduce the changes seen in Groups B and C by hyperventilation. Nine patients were studied, two from Group B-1, two from Group B-2, and five from Group C. In no instance did hyperventilation produce measurable RS-T segment depression or iso-electric or negative $\mathrm{T}$ waves.

Observer Error. The problem of observer error in electrocardiography has recently received attention (Thomas et al., 1958). It is not clear to what extent the reported divergencies have been due to true errors in observation, or to differences in interpretation of abnormalities that were agreed to be present. In this survey, the whole material was analysed twice by one observer (EDA) at an interval of more than a year. No reference was made to the first classification until the second was complete. As a result of the comparison it became clear that this observer found difficulty in distinguishing between "biphasic" and "inverted" $\mathrm{T}$ waves. The distinction was, therefore, abandoned and both anomalies were classified as "negative". In five cases, difficulty was experienced in deciding whether RS-T depression after exercise was limited to the RS-T junction or affected the whole segment (Fig. 1B). These cases were, therefore, relegated to Group D (unclassifiable). It was also found that two instances of RS-T depression of $0.5 \mathrm{~mm}$. had been missed on the first analysis. This was confirmed by an independent observer and they were classified in Group C. The composition of Group B was identical after each analysis.

\section{DISCUSSION}

The result of the survey shows that even when every precaution was taken to exclude persons with symptoms or signs of organic heart disease a few of the remaining men, all of whom appeared to be in good health, showed flat or sagging depression of the whole RS-T segment, or negative or iso-electric $T$ waves in cardiogram after strenuous exercise. Furthermore, when this depression amounted to $1 \mathrm{~mm}$. or more, it could be reproduced at a subsequent exercise test. This was usually true of inverted or iso-electric $\mathrm{T}$ waves. However, RS-T segment depression of $0.5 \mathrm{~mm}$. occurring alone was not always reproducible.

Negative or iso-electric $\mathrm{T}$ waves appearing after exercise in healthy persons have been reported on several occasions, particularly in lead II (Reindell, 1938; Tuttle and Korns, 1941; Barrow and 
Ouer, 1943; Ungerleider et al., 1943). However, only two instances of depression of the whole RS-T segment in similar circumstances are known to have been described (Reindell, 1938; Wood et al., 1950). According to Master (1950) such changes are due to excessive exertion. Within this survey there is a singular absence of support for this contention. Thus, these anomalies were as common after the single as after the double exercise, and those men who developed them did not exercise faster than those who did not, nor were they heavier, nor less accustomed to physical exertion.

The relative rarity of an electrocardiographic change does not by itself constitute a good reason for assigning it pathological significance. This is particularly true of changes in the $T$ wave which is notably labile and may be affected at rest by such factors as fright, cold, and posture (Levine, 1953). There is no reason to suppose that changes in the $T$ wave alone after exercise are any more reliable. Robb et al. (1956) showed that patients with a typical chest pain and isolated $\mathrm{T}$ wave anomalies after exercise had as good a prognosis as did those with normal tracings. In our material the majority of the instances of isolated $T$ wave changes occurred in the younger men. In four cases multiple premature beats or paroxysmal arrhythmias appear to have contributed to the changes. In view of these facts, it would appear unwise to attach much significance to them.

The difficulty in interpreting the RS-T segment after exercise has always been to separate the physiological effects of exercise from changes due to disease. The strongest argument for the view that the depression of the whole RS-T segment that occurred in some of the men studied may be related to latent myocardial ischæmia (rather than to the physiological effects of exertion) lies in its similarity to the depression seen in spontaneous attacks of angina pectoris. Thus, of the thirty-one reports that have been published of the cardiogram during spontaneous attacks of angina pectoris (Levy, 1929; Parkinson and Bedford, 1931; Siegel and Feil, 1931; Hall, 1932; Brow and Holman, 1933; Gray, 1934; Shapiro and Smyth, 1938; Wilson and Johnston, 1941), twenty-seven showed flat or sagging depression of the RS-T segment with elevation in the reciprocal lead in seven of these, three showed no electrocardiographic change during the seizure, and only one showed depression limited to the RS-T junction (Siegel and Feil, 1931). RS-T segment depression characteristically present in angina pectoris is seen in Fig. 6. Changes limited to the T wave have not, as far as we know, been reported under such circumstances.

Wood (1950) has gone so far as to describe flat or sagging RS-T depression of at least $1 \mathrm{~mm}$. after exercise as "ischæmic type depression", thus inferring that it is a specific diagnostic change. Robb et al. (1956) found that coronary occlusion developed subsequently nine times as frequently in patients with depression of the whole segment after exercise as in patients with no depression. The absence of chest pain in our subjects at the time RS-T changes were present does not necessarily negate our hypothesis as both Riseman et al. (1940) and Wood (1950) have shown that angina pectoris patients may develop typical electrocardiographic changes without chest pain. Further support may perhaps be derived from the fact that RS-T segment depression is commoner in the older man (Table II). In view of the finding of Doyle et al. (1957) and Dawber et al. (1957) that men with a high blood cholesterol are more likely to develop coronary occlusion subsequently than are those with lower levels, the higher mean cholesterol in Group B-2 in our material is interesting. However, the difference is of borderline significance and much weight cannot be attached to it.

It remains possible that a proportion of the examples of RS-T depression were due to some mechanism other than latent ischæmic heart disease. Aortic valve disease and thyrotoxicosis were ruled out on clinical grounds and anæmia was looked for but not found. Upper respiratory infections, gastro-enteritis, and the effort syndrome to which Master (1944) attributes some of his "false positives" were not present and it is highly unlikely that any of our men were taking digitalis or pitressin or were depleted of potassium (Levine, 1953). However, Packard (1952) has reported RS-T depression at rest both in the adults and children of a family without clinical evidence of heart disease and with a normal life expectancy. This indicates that such changes are not necessarily 


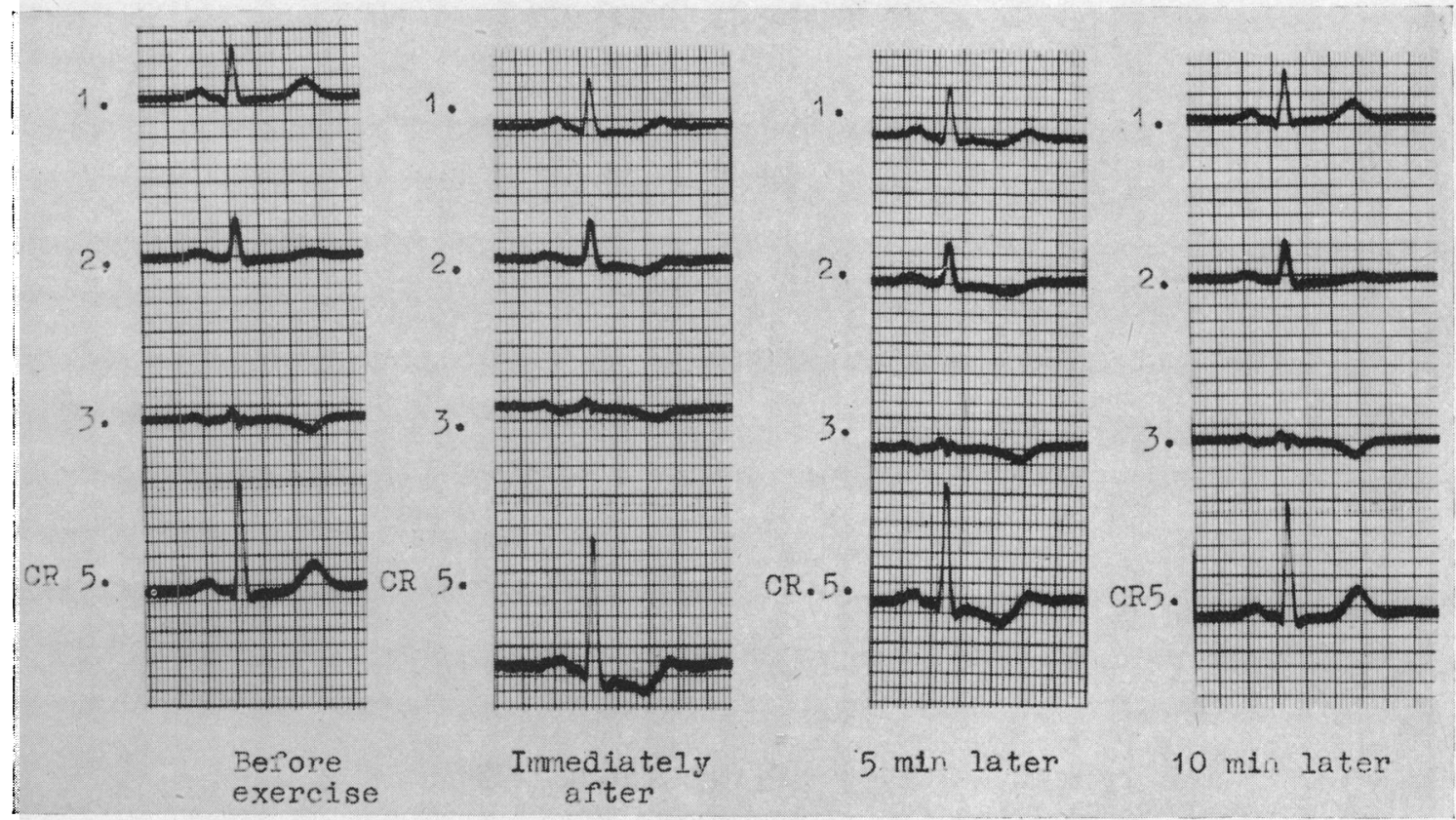

Fig. 6. - The cardiogram in a spontaneous attack of angina pectoris; from left to right: before onset of pain; in the early stage of the attack; as the pain was subsiding; and five minutes after pain had ceased.

specific. It is possible that temporary changes after exercise in the biochemical environment of the heart muscle may have been responsible but, if so, their nature is unknown and it remains to be explained why such changes should only occur in a small minority. In conclusion, it is fair to say that in 31 in Group B-2 the changes after exercise were such that, had the men suffered from chest pain, the electrocardiogram would have supported a diagnosis of ischæmic heart disease (Fig. 1 (c), 3, and 4).

The significance of " $\mathrm{J}$ " depression in the absence of other changes remains a subject of controversy. According to Wood (1950) it is a normal result of exercise. Others (Master, 1950; Scherf and Schaffer, 1952) believe that if exercise is carefully standardized, a figure can be set above which depression of " $\mathrm{J}$ " becomes a sign of ischæmia. Figures have been mentioned from $0.5 \mathrm{~mm}$. (Master, 1950) to $2.0 \mathrm{~mm}$. (Scherf and Schaffer, 1952). In this survey, "J" depression of $1 \mathrm{~mm}$. or more was so common that it seemed reasonable to regard it as a normal response to strenuous exercise. The difference in its pattern of distribution as compared with RS-T segment depression supports the view that it is caused differently, but it is worth noting that depression of the whole RS-T segment is commonly preceded by " $\mathrm{J}$ " depression. An association between these two phenomena has also been noted by Myers and Talmers (1955).

The subsequent clinical history of the whole group is being watched with interest and will be reported in due course.

\section{SUMMARY}

The results of an electrocardiographic survey are described. In a group of 660 men between the ages of 19 and 54 selected for their fitness, 570 (Group A) showed no depression of the RS-T segment and no iso-electric or negative $T$ waves. 45 (Group B) showed either depression of the whole RS-T segment of $1 \mathrm{~mm}$. or more or flat or negative T waves or both, after strenuous exercise. These changes were reproducible after an interval of weeks or months. This group 
was subdivided into 14 with isolated T-wave anomalies (Group B-1) and 31 with RS-T segment depression and $\mathrm{T}$-wave anomalies (Group B-2).

In addition, 25 men (Group C) showed border-line changes while in 20 instances (Group D) the tracings could not be classified.

Plasma cholesterol was estimated in 98 men from Group A and 32 men from Group B. The mean value was higher in Group B than in Group A, but the difference was not significant. However, the difference between the mean value for Group B-2 and the mean value for Group A was just significant.

Depression of RS-T junction ("J") of $1 \mathrm{~mm}$. or more after exercise was found in 50 per cent of 120 consecutive tracings in which it was studied. Figures are also given for the frequency of minor anomalies in the resting cardiograms, and for ectopic beats and arrhythmias after exercise. The significance of these findings is discussed.

The study is published by permission of the Director General of Medical Services. The authors wish to thank Dr. G. Mills of the Courtauld Institute of Biochemistry, Middlesex Hospital, for performing the cholesterol determinations. They also wish to acknowledge the cheerful co-operation of the officers and men of the Royal Air Force.

\section{BIBLIOGRAPHY}

Acheson, E. D. (1957). Lancet, 1, 26.

Barrow, W. H., and Ouer, R. A. (1943). Arch. intern. Med., 71, 547.

Bloor, W. T. (1916). J. biol. Chem., 24, 227.

Brow, G. R., and Holman, D. V. (1933). Amer. Heart J., 9, 259.

Dawber, T. R., Moore, F. E., and Mann, G. V. (1957). Amer. J. Public Health, 47, part 2, p. 4.

Doyle, J. T., Heslin, A. S., Hilleboe, H. E., Formel, P. F., and Korns, R. F. (1957). Amer. J. Public Health, 47, part 2, p. 25.

Gray, M. K. (1934). Brit. med. J., 1., 847.

Hall, D. (1932). Lancet, 1, 1254.

Jencks, W. P., Hyatt, M. R., Jetton, M. R., Mattingly, T. W., and Durram, E. L. (1956). J. clin. Invest., 35, 980.

Keys, A., Mickleson, O., Muller, E. V. O., Hayes, E. R., and Todd, R. C. (1950). J. clin. Invest., 29, 1347.

Lawry, E. V., Mann, G. V., Peterson, A., Wysocki, A. P., O'Connel, R., and Seare, F. J. (1957). Amer. J. Med., 22, 605 .

Levine, H. O. (1953). Amer. J. Med., 15, 344.

Levy, R. (1929). Arch. Mal. Cour, 22, 523.

Liebermann, C. (1885). Ber. dtsch. chem. Ges., 18, 1803.

Manning, G. W. (1954). Circulation, 10, 401.

Master, A. M. (1950). Ann, intern. Med., 32, 842.

Master, A. M., Nuzie, S., Brown, R. C., and Parker, R. C. (1944). Amer. J. Med. Sci., 207, 435.

Myers, G. B., and Talmers, F. N. (1955). Ann. intern. Med., 43, 361.

Oliver, M. F., and Boyd, G. S. (1953). Brit. Heart J., 15, 387.

Packard, J. M., Graethinger, T. S., and Graybiel, A. (1954). Circulation, 10, 384.

Packard, J. M. (1952). Report from U.S. Naval School of Aviation Medicine.

Parkinson, J., and Bedford, D. E. (1931). Lancet., 1, 15.

Reindell, H. (1938). Deutsches Archiv. klin. Med., 182, 506.

Riseman, J. E. F., Waller, T. V., and Brown, M. G. (1940). Amer. Heart J., 19, 683.

Robb, G. P., Marks, H. H., and Mattingley, T. W. (1956). Trans. Assoc. Life Insurance Med. Directors of America, 40, p. 52 .

Scherf, D., and Schaffer, A. I. (1952). Amer. Heart J., 43, 927.

Shapiro, H. H., and Smyth, L. A. (1938). J. Lab. clin. Med., 23, 819.

Siegel, M. L., and Feil, H. (1931). J. clin. Invest., 10, 795.

Thomas, A. J., Cochrane, and A. L., Higgins, I. T. T. (1958). Lancet., 2, 540.

Tuttle, W. W., and Korns, H. M. (1941). Amer. Heart J., 21, 104.

Ungerleider, M. D., Duligg, T. F., and Gubner, R. S. (1943). U.S. Nav. Med. Bull., 41, 441.

Wasserburger, R. A., and Lorenz, T. H. (1956). Amer. Heart J., 51, 666.

Wilson, F. N., and Johnston, F. D. (1941). Amer. Heart J., 22, 64.

Wood, P., McGregor, M., Magidson, O., and Whittaker, W. (1950). Brit. Heart J., 12, 363. 